\title{
The Uneven Regional Development Impacting on the Process of Thailand's Modernization
}

\author{
Liu Meiwu* \\ International Business School \\ Yunnan University of Finance and Economics \\ Kunming, China \\ lmwkm11@sina.com
}

\author{
Chen Weilin \\ Chulalongkorn University \\ Bangkok, Thailand \\ cw193523cc@gmail.com
}

\begin{abstract}
This paper based on the situation of Thailand's uneven regional development and the modernization process which during a period from 1980s to 1990s. As a most controversial period of Thailand's modernization, the remarkable economic achievements of these two decades had attracts the attention of the world and also caused most serious uneven development of interregional. After gone through an economic take-off period, the social problem which caused by uneven regional development had appeared more directly after the explosion of Asia financial crisis. The article expounds the main social problem caused by uneven regional development, and analysis relevant data like 'Per Capita Household Income by Region' or 'Percentage of population below poverty live in Thailand by regional'. According to the fact of income inequality and increased poverty population, the paper will from the perspective of mutual reaction to probe how uneven regional through an indirect way to effect the Thailand's modernization process in 1980s and 1990s.
\end{abstract}

Keywords-uneven regional development; modernization; income inequality; mutual interaction; Thailand

\section{INTRODUCTION}

During 1980s to 1990 s, we can saw a great socioeconomic transformation in different Asia country due to advances in new world economic pattern and globalization. In Asia, this period, Japan rose from the ruins of the Word War II to become the second strongest economy in the world and experienced a special stage of rapid economic growth and recession; China reopening to the world with the new socialeconomic reform after through a long domestic political struggle; Four Asia Tiger maintaining exceptionally high growth rates and rapid industrialization during this period and their economic success stories later have served as role models for the Tiger Cub Economies. As a developing country try to step out of the shadows of the Cold War, fortunately, Thailand had caught the opportunity of Asia's economic boom which led by Japan's economic miracle and Four Asia Tiger economies.

Socioeconomic transition during this period largely depends on moderate military rule of Prem government in late 1980s [1]. Over the 1980s, Japanese foreign investment exceeded that from the US by almost three times. As multiple multinational corporations associated with the manufacturing industry relocated into Thailand especially in the Greater

\footnotetext{
* Corresponding author
}

Bangkok area, a large amount of rural labor force were drawn away to the Bangkok again [2]. But most of this rural labor force were comes from the poorer northeast where just through a hardest period of worst agriculture declined in 1970s. With continuing scale expansion of big conglomerate and thousands of small sized companies, and soon the demand of highranking technician and professionals had push the rapid development in tertiary education in Thailand. As the growth demands of talent market, a plenty variety of public and private university were established in late 1980s. High salaries of commercial area and financial area also lead a craze in tertiary education to learning practical technical skills such like business administration, accountancy and financial management.

Most of these developments in large degree benefited from the relatively stable political situation which maintain by Prem government. Stable political situation had provided a foundation for social stability which created the favorable conditions for Thailand's transition period. Contemporaneity, in the late 1980s, with different shock among the economic development, social structural transformation, world pattern changed and the high demands of people in political democratization, the foundation of military rule in Thailand had shaken. Into the early $1990 \mathrm{~s}$, democratization movement had pushed to the climax in Thailand. After through four years political transitional, with the Chuan Leekpai government established, Thailand had entered in a transition stage of democracy. Even Black May in 1992 had caused billions of dollars in damaged, but political unrest still cannot obstruct the rapid development of Thailand's economic. The three consecutive annual growth rate of Thailand's GDP had exceeded 10\% between 1988 and 1990. After 1991, the annual growth rate of GDP still kept exceeded 8\% until the Asian financial crisis occurred in 1996 . (1) Economic liberalization as the core of the government economic policy led Thailand traditional resource and labor intensive industrial structure forward to technology and capital intensive industrial structure. Growing urban demand and easy access to markets enable the remaining farmers to move into higher-value cropping patterns. Later on, amount of hot money through various channels into Thailand and it raising the high investment enthusiasm of speculator in financial and real estate in early 1990s [2]. The whole country had into the Golden Age of economic and construction development before the Asian financial crisis. 
Simultaneously, with the development of communication technology, mass media as the major medium led the concept of globalization entered into Thailand's mass society in 1990s. Mass media gradually become a part of people's day life and it also became a medium reflection the multi characteristics of nationalities make up, the diversity of social culture and the potential crisis of economic development in Thailand.

When all the middle classes, bureaucrats and nobilities of this country immersed in the delight for acquire wealth from the Golden Age of economic, the Asian financial crisis poured a huge pool of cold water to Thailand's economic development in 1996. The entire social problem seems appeared overnight. During this period, the Great Bangkok area had been through a dramatically process of modernization, other region in this country still cannot have a chance to share the benefits from rapid economic development but had to take upon the serious consequences for this crisis. A large number of rural labor force been unemployed and back to their villages again. In order to step out the shadow of Asia financial crisis, in 1997, Chuan Leekpai returned to politics with his government formulated positive national economic policy as a protection to the process of economic modernization. Stable growth rate of GDP between 1997 and 2004 seems told people the modernization process in Thailand already got back on track again. However, Thailand was constantly faced toughest test on account of the restriction in comprehensive national strength. Due to over-concentration of industrialization and failure to recognize the importance of infrastructure construction since 1980 s, the remote region in Thailand such like northeast region had missed the opportunity to catch the tail of economic boom in the Greater Bangkok area. A obviously gap of economic development, urban construction and industrial construction in different region had appeared. Quickly, the uneven regional development gradually became a main obstacle of modernization process in Thailand. Social wealth distribution inequality, equal employment opportunity and equity of educational opportunity which caused by uneven regional development in Thailand had intensified social contradictions in later twenty years.

The uneven development is a term used within later Marxist theory to denote the process by which capitalism transforms the world as a whole but does so in different ways, developing the productive and social forces in some areas, but restricting or distorting growth in others. It may be contrasted with the earlier Marxist belief in capitalism as producing a uniform world in its own image. The differing conceptual emphases are paralleled by debate surrounding the origins and socioeconomic mechanisms of unevenness. Neil Smith (1990, chapter 3 ) rooted the equalization and differentiation of capital --the fundamental motions of uneven development--in the widespread emergence of the division of labor. Ernest Mandel (1968, page210) searched even further back, to "private production" among different producers within the same community; insisting that "differences of aptitude between individuals, the differences of fertility between animals or soils, innumerable accidents of human life or the cycle of nature," were responsible for uneven development in production. In follow part, the article will combine with the perspective of modernization process in Thailand, from different aspects to analysis and probe the reason which caused uneven regional development [13].

\section{RESTRICTION OF OBJECTIVE NATURAL CONDITION}

As a tropical country in Indochina Peninsula, according to the difference of climate, topography and ecology, the region definition is divided by natural geography feature of four main regions in Thailand: southern, central, northern and northeast. In geographical conditions, the central region of Thailand is a fertile alluvial plain which Chao Phraya River had run northto-south through the whole central plain. Either of the traditional agricultural era or post-war industrialization era, the central region in Thailand always was a core region of economic and political which mainly advantaged by its favorable natural conditions. In northern Thailand, the major landform is rugged mountains and hills. Naturally, the northern region strength lies in its vast reserves of timber resources and mineral deposit. On the other hand, northern region also as an important role in Thailand's national strategy natural reserve. Back into the history of Southeast Asia, the cultural development of the people of the Northern Thailand had begun long before as successive kingdoms preceded Lan $\mathrm{Na}$. On the contrary, the composition of the northeast region is a huge basin, usually called Korat Basin which nearly accounts for $30 \%$ percent of the Thailand national land area. Due to its poor natural conditions, this region was mainly covered by undulating landform and jungle. Nowadays, northeast people are still struggling with infrequent rains and poor soils fertility. Southern Thailand is a long peninsula, stretching down to Malaysia and bordered by the Gulf of Thailand and the Andaman Sea. Abundant rainfall and fertile soil in large degree created the favorable natural conditions for rubber plantations and extensive tin ore.

To some degree, difference of natural condition could decide different starting points of economic and industrialization development. However, as public infrastructure construction could not produce direct economic benefits, it is often ignored in the process of modernization. Because of this, the neglect of Thailand government in infrastructure construction had led an embarrassing situation of national industrial distribution in 1980s. From the perspective of four regions comprehensive conditions, alluvial plain always as a reasonable site for ancient civilizations, and the favorable natural conditions of Thailand central region had created the definite advantages in production costs, especially in cost of labor force and transportation. Therefore, even though northern and northeast region had abundant untapped natural resources, the lack of infrastructure construction and poor natural conditions like a hard stone block the foreign investment. Because, the capital always chasing maximizing of profits, no one of them willing to spent high construction cost even could to be a first 'gold digger'.

\section{Passive Transition Process of Economic Modernization, Policy SElECTION OF RULERS AND POLITICAL TRANSITION}

The origins of Thailand's modernization still have controversial in academia to this day. But neither in the stages of signs Bowring Treaty or Chulalongkorn's reformation period, the original motive of Thailand's modernization did not 
come from the internal innovation which led by social force. On the contrary, the real original motive of Thailand's modernization are mainly come from the political and economic reformation which effected by exogenous shocks. According to the modernization theory, Thailand's belongs to exogenous modernization [5]. The productivity elements and cultural element of exogenous modernization are introduced or transplant from developed countries, especially under the foundation of dependencies between the industrial manufacturing and products export. During 1980s, the industrialization construction of Thailand was mainly relied on investment of foreign capital, and this factor in large degree had limited the growth of the internal economic operational mechanism.

The immaturity of domestic market and the restriction of economic autonomy capability let the investment of foreign capital were highly clustered in the Great Bangkok area, and the economic policy also could not effectively to drive capital into the northern and northeast region. But the government was not entirely inactive to improve the uneven development in different region. According to the third five-year plan of Thailand, the governments had pay attention to regional industrial distribution and formulated relevant policy as early as 1972-1976, and established Industrial Estate Authority in 1972. However, the third development plan placed special emphasis on improvements in the rural infrastructure, growth in the financial and commercial sectors, and further assistance to crop diversification and to import-substitution industries. Therefore, the third five-year plan had not directivity impact the improvement of uneven development in different region. Until the fifth five-year plan (1982-1986), the plan transfer to emphasized decentralization of industry and economic growth from the capital region to the provinces. The relevant terms about encourage disperation of industry into other province in Thailand suggest that the government will promote small scale industry into the basic foundation for the country's industrial development, and at the same time it will speed up industrial decentralization to provincial areas in order to disperse economic activities and increase the use of local natural resources. This will be accomplished in concert with the regional and regional urban development plans'. Following closely, in the sixth five-year development plan (1987-1991), government stressed reduction of rural poverty and social tensions and expansion of employment opportunities in the poorer regions. If we just use each five-year plan as a main referential indexes from macro perspectives. It is undeniable that Thailand government had pay attention in regional industrial distribution from very beginning. But it's clearly to see when we combining relevant policy of the coping style in uneven regional development what the Thailand government had formulated, the major terms of regional developing policy were centred on Industrial construction and investment.

In later 1980s, with different shock among the economic development, social structural transformation, world pattern changed and the high demands of people in political democratization, the foundation of military rule in Thailand had shaken. After through four years political struggle (19881992), with the established of Chuan Leekpai government in 1992, the military rule had been Weaken and the social democratization had taken to a new level. However, implementation democratization is not an overnight process. Even though the government had follow the model of western countries used unbalance development strategy to let uneven development pushed balanced development, the instability and defective of regime in Thailand still could not provide a stable foundation for the balanced social development and market control. With the advantages of political democratization and economic liberalization which from the political transition period, the foreign capitalists, conglomerate and upper class group became the first beneficiaries and the lower class group who lived in remote region had not shared this flourishing period. The interests differentiation from each class gradually hard to control. After the Asia financial crisis, improvement of uneven regional development as an important plan had retakes to the government development strategy. But the class interests which given rise to an internal class struggle in later 1990s. Subsequently, even though Taksin take the his new reformation plan to improve the infrastructure construction in rural region and pay more attention in uneven regional development, the complex struggle of class interests and political power in a large degree let the improvement of uneven regional development didn't come to fruition.

From the above, first, the process of early remote regional development is restricted by exogenous modernization model. Due to the low starting point of modern technology in 1980s, Thailand is hard to completely copy the western economies or Japan's development path. With a large inflow of foreign capital into domestic market and the over concentration investment in the Great Bangkok area had bequeathed potential threat in remote regional development from very beginning. Second, in early 1980s, the investment policy could not effectively combined with practical situation of Thailand remote areas, and over-emphasis of industrialization in early stage of national economic development strategy had ignored the real development degree of regional supporting construction. Therefore, the trends of regional growing gap cannot improved in the nascent. Then, when we review the economic development trend in Thailand during these two decades, it will easy to find that government had spent a lot of attention to concentrated on rapid annual growth rates of GDP and confused the temporary economic success of government's eyes to blind to take another 'hand' resolve conflict in uneven regional development. Until the Asia financial crisis struck successive Thailand governments had been focusing on formulate overall social development rather than economic development only. Last, the long term political dilemma in Thailand couldn't to provide a stable social foundation for the balanced social development. In these two decades, the complex struggle of class interests and political power also became a huge obstruction to let the whole country were distraction too much energy on struggle of political power rather than the development of modernization process and a series of social problems in Thailand also arose from here. In the follow part, I will expound the main social problem which caused by uneven regional development with the analysis of relevant index and statistical reports. 


\section{REGIONAL INCOME INEQUALITY AND POVERTY POPULATION}

The pattern of development in Thailand was already markedly uneven by 1940 - Bangkok and the adjacent areas of the Central Plain being significantly more wealthy and commercialized than the rest of the kingdom. While this trend had been noticed half a century ago, but during these two decades of economic boom, the uneven regional development had attracted the attention of government until early 1990s [9]. After gone through an economic take-off period, with the explosion of Asia financial crisis, the social problem which caused by uneven regional development had appeared more directly.

TABLE I. Per CAPITA Household InCOME By Region AND AREA: 1981-1998(BAHT)

\begin{tabular}{|l|l|l|l|l|l|l|l|l|}
\hline Region & 1981 & 1986 & 1988 & 1990 & 1992 & 1994 & 1996 & 1998 \\
\hline $\begin{array}{l}\text { Greater } \\
\text { Bangkok }\end{array}$ & 1,422 & 1,829 & 2,251 & 3,257 & 4,691 & 4,975 & 6,879 & 7,806 \\
\hline Central & 852 & 954 & 1,082 & 1,457 & 1,817 & 2,358 & 2,954 & 3,500 \\
\hline North & 700 & 796 & 919 & 1,242 & 1,420 & 1,789 & 2,362 & 2,736 \\
\hline Northeast & 493 & 521 & 682 & 784 & 1,052 & 1,366 & 1,807 & 2,089 \\
\hline South & 740 & 871 & 966 & 1,171 & 1,557 & 1,955 & 2,500 & 2,911 \\
\hline $\begin{array}{l}\text { Whole } \\
\text { Kingdom }\end{array}$ & 751 & 844 & 1,027 & 1,372 & 1,811 & 2,174 & 2,890 & 3,378 \\
\hline $\begin{array}{l}\text { Municipal } \\
\text { Areas }\end{array}$ & 1,451 & 1,751 & 1,801 & 2,307 & 3,337 & 3,656 & 4,944 & \\
\hline $\begin{array}{l}\text { Sanitary } \\
\text { Districts }\end{array}$ & 787 & 980 & 1,129 & 1,451 & 2,011 & 2,370 & 3,502 & \\
\hline Villages & 583 & 595 & 736 & 929 & 1,144 & 1,501 & 1,933 & \\
\hline
\end{tabular}

While the regional income inequality did not appeared first time, but the income gap of different region in Thailand had been more obviously than ever during 1980s-1990s. One of the most important aspects of income inequality in Thailand is the regional income gap, which accounts for about $20 \%$ of income inequality of the whole kingdom. The table one shows the per capita household income by region and area during 1981-1998, all the data are come from the NSO (National Statistics Office). According the table one, Thailand had been divided by five regions is Greater Bangkok, Central, North, Northeast and South. Overall, the per capital household income of each region had increased of different degrees. In early 1980s, the income among different region was sufficiently obvious. For example, regional income inequality had increased between Greater Bangkok and Northeast since 1981, and the maximum gap appears in 1992. During this period, the income gap of Greater Bangkok and Northeast rapid increased from 2.89:1 to 4.46:1. Although the income gap between these two areas had narrowed to $3.64: 1$ in 1994 , the huge income disparity still very clearly. During this period, the per capita household income between North and South region is very close, but compare with Bangkok and Central region, the huge income gap of them also exist.Furthermore, in table one, the Thailand had divided into three categories of area were municipal areas, sanitary districts (semi-urban area) and villages. As municipal areas mainly concentrated in Greater Bangkok and the semi-urban area more concentrated in Central region, it's easy to find a similar trend in the income disparity between municipal areas and rural areas. The regional income inequality shows more clearly in this aspect. The income gap of municipal areas and villages had widened since early 1980s, but narrowed down after 1994. Therefore, in one way or another, economic boom in 1980s-1990s had directly influenced the increasing of per capital household income in each region. But on the other hand regional income inequality also become the most negative results which effected by uneven regional development.

TABle II. Percentage of Population Below Poverty Live IN THAILAND BY REGIONAL: 1990-2000

\begin{tabular}{|c|c|c|c|c|c|c|c|}
\hline Region & Area & 1990 & 1992 & 1994 & 1996 & 1998 & 2000 \\
\hline \multirow[t]{2}{*}{ Bangkok } & Urban & 11.90 & 04.39 & 04.11 & 01.21 & 01.23 & 01.71 \\
\hline & Total rate & 11.90 & 04.39 & 04.11 & 01.21 & 01.23 & 01.71 \\
\hline \multirow[t]{3}{*}{ Central } & Urban & 22.34 & 10.80 & 09.04 & 05.42 & 04.72 & 07.04 \\
\hline & Rural & 27.84 & 21.84 & 12.17 & 06.48 & 09.36 & 10.07 \\
\hline & Total rate & 26.12 & 18.31 & 11.15 & 06.13 & 07.80 & 09.03 \\
\hline \multirow[t]{3}{*}{ North } & Urban & 27.82 & 19.12 & 19.06 & 13.41 & 14.10 & 16.11 \\
\hline & Rural & 37.11 & 36.25 & 21.18 & 18.96 & 17.08 & 24.87 \\
\hline & Total rate & 35.19 & 32.73 & 20.75 & 17.83 & 16.47 & 23.10 \\
\hline \multirow[t]{3}{*}{ Northeast } & Urban & 31.14 & 24.59 & 15.42 & 14.95 & 17.16 & 20.07 \\
\hline & Rural & 48.65 & 44.06 & 30.36 & 26.32 & 33.25 & 38.36 \\
\hline & Total rate & 46.09 & 41.14 & 28.07 & 24.54 & 30.67 & 35.34 \\
\hline \multirow[t]{3}{*}{ South } & Urban & 18.64 & 11.76 & 10.61 & 07.12 & 06.69 & 05.72 \\
\hline & Rural & 31.67 & 28.71 & 19.77 & 11.19 & 16.07 & 19.86 \\
\hline & Total rate & 29.03 & 25.19 & 17.82 & 10.31 & 13.98 & 16.64 \\
\hline \multirow[t]{3}{*}{ Thailand } & Urban & 20.46 & 12.11 & 09.88 & 06.84 & 07.14 & 08.63 \\
\hline & Rural & 39.20 & 35.33 & 22.87 & 18.19 & 21.99 & 26.49 \\
\hline & Total rate & 33.69 & 28.43 & 18.98 & 14.75 & 17.46 & 20.98 \\
\hline
\end{tabular}

To further illustrate how the uneven regional development had directly influenced regional income inequality, the follow part will use a different perspective to compare the trend of per capita household income and percentage of population below poverty live in Thailand. The table two is percentage of population below poverty live in Thailand in each region during 1990-2000. After analyze the poverty population rate of each region during this decade, it's clear to see that the rates of poverty population in whole Thailand had decreased more than $10 \%$. However, when we change the focus in compare the situation of each region, it's also clear to see that the gap of rich and poor between Bangkok area and other region had extremely increased. Take Bangkok area and Northeast area for example, in 1990, the ratio of poverty population in Bangkok was 100:12 and in Northeast was 100:46. The poverty group in Bangkok had occupied one fifth of total population, but it had nearly take up half of the total population in Northeast at same time. Then, up to 2000, the ratio of poverty population in Northeast had decreased in 100:35 and in Bangkok was less than 100: 2. Even though the rates of poverty population had both decreased in two regions, the interregional gap of rich and poor had sharp increased. When we looking at the change of poverty population distribution in all area, the total rate of poverty population in North and Northeast area was still lower than national average until 2000. In consequence, the poverty population was mainly concentrated on North and Northeast region at end of 1990s. 


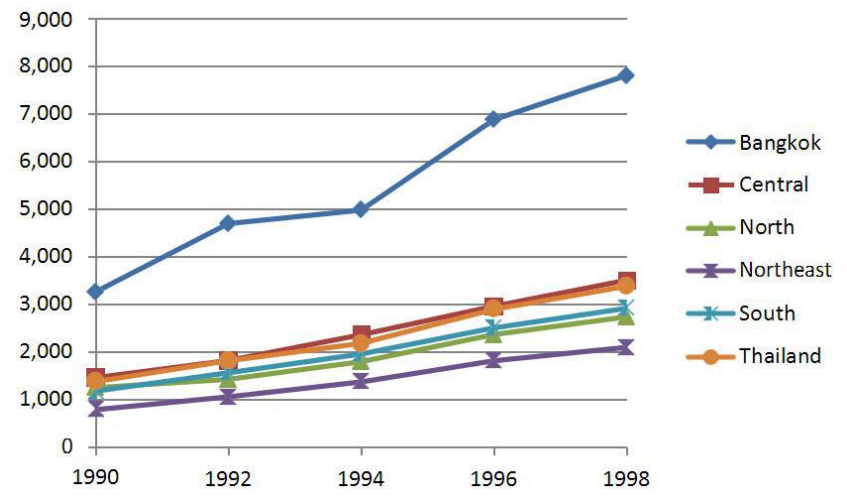

Fig. 1. Per Capita Household Income by Region and Area: 1990-1998(Baht)

Source: from Table I

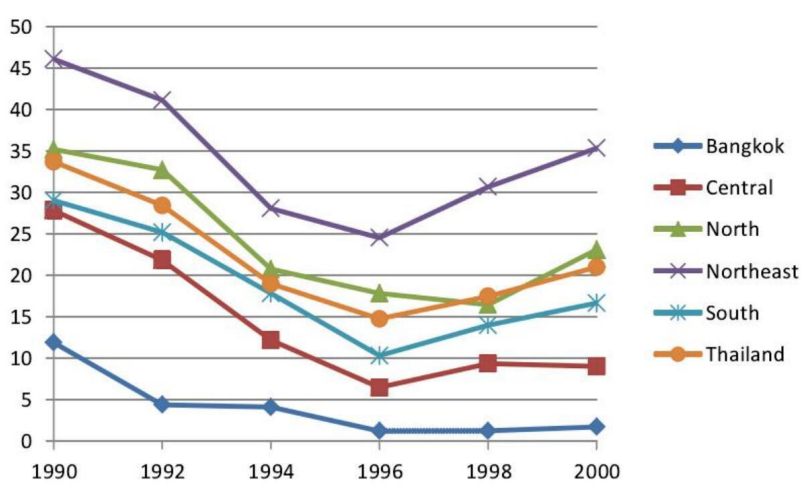

Fig. 2. Percentage of population below poverty live in Thailand by regional: 1990-1998

Source: from Table II

The two charts are comparing the trend of per capita household income (chart 1) and percentage of population below poverty lives in Thailand (chart 2). For comparison, the data of both charts was selected from 1990 to 1998. The fast growth of per capita household income in Bangkok had pushed the ratio of poverty population drops quickly. Base on the pattern of uneven development in western countries, they tend to use policy encouragement by push the development first of modernization process in developed area and then led the development of backward area. Nevertheless, rapid income growth of Bangkok area could not effectively led the income growth in other region. In other word, the economic boom in Bangkok area did not driven the economic development in remote areas apparently. On the contrary, the regional income inequality which caused by uneven regional development had widened the gap of poverty population in each region indirectly.

If combined with the above data and Thailand's domestic situation in 1990s, the immediate impact of uneven regional development will easier to explain. With the increasing construction of industrialization in early 1980s, it had laid the foundation for the economic boom in later period. In early 1990s, uneven regional development had led an extremely trend and widen the gap of per capita household income between Bangkok and other regions. But on the other side, the decreasing of poverty population was also benefited by Thailand's economic boom, especially reflected in Northeast region. However, the ratio of poverty population had rebounded in varying degrees after Asia Financial Crisis broke out in 1997. As can be seen of above chart, due to the Asia Financial Crisis had inflicted heavy losses on manufacturing industries which were mainly concentrated on Bangkok and Central area, it also had influenced rebounding degree in different region. According the rebounding of population rates is not hard to speculate that a large amount of rural labor force whose were come from North, South and Northeast area had taken the hit of financial crisis. And this trend in Bangkok area was not obvious. In short, the uneven regional development had occurred in Thailand's economic boom period, it had directly widened the gap of interregional per capita household income. A large amount of foreign investment concentrated on Great Bangkok area had increased the demand of labor force and created more job opportunity for rural people who come from Northeast and North region. At the same time, capitalist, speculator and upper class who lived in Bangkok had taken this chance to build further social wealth under their existing basis. Hence, when financial crisis happened, the adverse impact of economic recession not only the capitalists had suffered great losses but also take the job opportunity away of the lower class who had abandoned land farming. Subsequently, with the transformation of industrial structure and the influence of globalization, the developmental level of infrastructure, industrial construction, education and human resources had become an aggregative indicator of new overseas-funded enterprises to evaluate the value of investment. As a result, the remote region such like Northeast region had lost another development opportunity due to its backward situation.

\section{POVERTy Group. Where to Go?}

When backtrack to later 1970 s and early 1980 s, the critical period for Thailand's paradigm changing from agriculture-lead to manufacturing-led, the high demand of labor-intensive industries had attracted millions of rural labor come to Bangkok and Central area. On the basis of the Survey of Children and Youth (Thailand, NSO 1977 and 1983) had also found that students in urban areas tended to attend tertiary education than rural children. Nearly 60 percent of youths aged 15-19 were still in school in urban areas, whereas the corresponding figure for rural youths in that age group was a mere 20 percent. The reason which caused this kind of phenomenon is from many different ways [9]. But it is also hard to deny that family financial difficulty was a major reason for poor family could not afford their children to continuation into high level of education. When all these youth who followed the step of economic boom and swarm into Bangkok and Central area in early 1980s, it had provide a huge poor of cheap labor market and it also as a strong foundation to support construction of labor-intensive industry. After experienced a stage of remarkable economic growth and structural change from the mid-1980s to early 1990s, the Bangkok and Central area had gathering tens of millions of labor force. However, as the upgrading of industrial structure and technological innovation in Bangkok which following the Asia financial crisis had reduced the market demand for low-skilled labor 
force, the urban industrial sector appears incapable of providing gainful employment for the estimated 10 million people who will leave the agricultural sector by early next century [14].

With the recession of labor-intensive industry, without professional skills and the lack of knowledge had put those low skilled labor forces into a predicament. The uneven regional development which occurred in economic boom had directly caused the unbalanced level of urbanization in remote region such like Northeast. The poor conditions of their hometown let those people who already used to live in metropolis were unwilling back to rural area again. In addition, the poor natural condition of these remote regions and high time cost of agricultural cultivation also became a main reason to lead this group escape rural area. But with the increasingly fierce market competition, the problem of deficient in industry structure upgrading and technology innovation which exposed after Asia financial crisis makes labor intensive industries lose advantages in Thailand, and soon many manufacturing enterprise through a large-scale layoff. Although Thailand's unemployment rate is difficult to determine, government officials currently estimate that it has reached two million, with at least 2,000 workers losing their jobs every day. And those low skilled labor forces had occupied the main part of unemployment group [12]. Combine with the data of the follow table 3, until 2000, the population aged 6-24 years of not attending the school still had accounted for over one third of overall populations, and the average years of education attainment of population aged 15 years and over were at 9.7 years which equivalently in secondary level. On the other side, the population in the agricultural sector had decreased from $2.5 \%$ to $1.5 \%$ during these decades. As mentioned in chart two, a strong rebound trend of poverty population after Asia financial crisis were mainly concentrated in the northeast region where was the major source of low-skilled labor in Bangkok and Central area. And those large poor group who were leaved agricultural sector and without enough education attainment and professional skill had indirectly had bearded the huge brunt of this crisis. At the same time, in 1997, the Ministry of Labour and Social Welfare had launch relevant skill training program to provide for specific groups, who don't have opportunity to enter formal educational systems. But due the age of these low skilled labor who escaped villages in early 1980s were almost exceed 35 years old in later 1990s [15]. But, those skill training program are mainly focus on cultivate the young labor force.

TABLE III. KEY INDICATORS OF THE POPULATION AND HOUSEHOLdS, PopUlation AND Housing CENSUS, 1990 AND 2000

\begin{tabular}{|c|c|c|c|c|}
\hline \multicolumn{6}{|c|}{ Demographic characteristics } \\
\hline year & Total population & $0-14$ years (\%) & $\begin{array}{l}15-59 \text { years } \\
(\%)\end{array}$ & $\begin{array}{l}60 \text { years and } \\
\text { over (\%) }\end{array}$ \\
\hline 1990 & $58,824,000$ & 21.5 & 72.5 & 6 \\
\hline 2000 & $63,551,000$ & 17.5 & 74.6 & 7.9 \\
\hline Education & $\begin{array}{l}\text { Average years of education } \\
\text { attainment of population aged } \\
15 \text { years and over (\%) }\end{array}$ & $\begin{array}{c}\text { Population aged 6-24 } \\
\text { year }\end{array}$ & \begin{tabular}{c}
$(\%)$ \\
\hline
\end{tabular}
\end{tabular}

\begin{tabular}{|c|c|c|c|c|}
\hline 1990 & & 8.8 & & 43.5 \\
\hline 2000 & & 9.7 & & 35.3 \\
\hline year & \multicolumn{2}{|c|}{$\begin{array}{l}\text { Population in the agricultural secto } \\
(\%)\end{array}$} & & \\
\hline 1990 & & 2.5 & & \\
\hline 2000 & & 1.5 & & \\
\hline \multicolumn{5}{|c|}{ Employment characteristics of population: work status (\%) } \\
\hline year & Employers & $\begin{array}{c}\text { Own account } \\
\text { works }\end{array}$ & Employees & $\begin{array}{l}\text { Unpaid } \\
\text { family }\end{array}$ \\
\hline 1990 & 3 & 15.8 & 73.5 & 7.7 \\
\hline 2000 & 4.4 & 17.9 & 70.3 & 7.2 \\
\hline
\end{tabular}

In some sense, those group who lack enough education attainment and professional skills had missed opportunity again to learn a basic skill to make living. In addition, with the increasing trend of uneven regional development, the backward of urbanization and industrialization in remote region also shows incapable of providing enough job opportunity to this group. Therefore, in late $1990 \mathrm{~s}$, the "mess" situation put those people into a tough dilemma. From my perspective, while the strong rebound of poverty population could not directly deduced caused by uneven regional development, but uneven regional development like a fuse through a chain effect model had finally triggered a series of problem to hindered the modernization process of Thailand during 1980s to 1990s. In these two decades, combined with the global context and domestic condition, the interaction effect between modernization process and uneven regional development in Thailand had appeared extremely than ever.

\section{INTERACTION EFFECT BETWEEN MODERNIZATION Process AND UneVEn Regional DeVElopment: Mutual PROMOTION AND MUTUAL RESTRICTION}

The tremendous shift over these two decades in Thailand is controversial until today. A series of social contradictions appeared which followed remarkable economic growth. Based on the Marxist theory, uneven development could not balance every side for social development. Combined with the condition of Thailand from 1980s to 1990 s, the interaction effect between modernization process and uneven regional development could analysis with two angles.

From the perspective of mutual promotion, uneven regional development strategy had effectively driven the economic boom in Bangkok and Central area. As an indispensable period for socioeconomic structure transformation, the prosperous of Bangkok had led the first-step developing and laid a foundation to support the continuative development of remote region. In early 1980s, the uneven regional development strategy had centralized resource in Bangkok and with the strong industrial transformation as well as brought a million of job opportunities into there. Subsequently, the vigorous expansion of manufacturing industry and urbanization which benefited by foundation of vast labor market had triggered the technology innovation and inner demand of soft power in modernization process. Then, the emergence of inner demand had reformed in political institution, education system and diversified social 
culture. Followed the step of this, with the improvement of urban infrastructure, it also had laid a foundation for living quality and attract more opportunities into metropolis. When the development pattern had settled down in central region of Thailand, it had gradually entered a stage of balance resource distribution in early 1990s. Soon, the driven force of inner demand latterly pushed the development of industrial transformation changed from a manufacturing-led industry period into a service-led industry period. While it is too onesided through that rapid growth rate of GDP to judge the achievement of Thailand's modernization process in early 1990 s, but the interaction effect by a promotion way had effectively increased social force to driven the modernization process is also undeniable.

Nonetheless, the uneven regional development had taken serious interlocking effect in later 1990s. From the perspective of mutual restriction, the negative impact of uneven regional development more likely an indirect processes to hinder the balance development of modernization process. The huge gap of interregional development had taken the regional development pattern into an infinite loop. At the same time, the over- concentrated pattern of modernization process let the basic demand of poverty group been marginalized. When whole countries were emphasize particularly on industrial transformation and pay a lot of attention on industrial construction and developing manufacturing, the ruler and government had ignored a important fact that a high proportion of rural labor force were dependent on agricultural. To some extent, in mid-1980s, the high demand of cheap labor market which effected by rapid economic growth had provide nearly a million of temporary job opportunities for those rural poverty group to make living. But without sufficient education attainment and professional skill, those people who are used to dependent on agriculture had been eliminated when financial crisis broke out. And the over-quick transition stage of agriculture in later 1970 s did not leave adequate time to lay a stable foundation help accomplish this transition period entirely. The rapid decline in the importance of agricultural production has not yet been matched by a corresponding fall in the sector's share of employment. In consequence, as increasing seriousness gap of social income distribution and add a pool of poverty group that are left in the rapid uneven regional development, the formation of social obstruction like an interlocking process from quantitative changes to qualitative changes which finally had produced huge effect of mutual restriction between interregional development and modernization process [9]. When entered 2000, the income inequality which caused by wealth gap had deepen the class division in Thailand. The serious division of different social class had trigger a series of social rights conflict which results in a long term instability phenomenon of Thailand's political situation. The turbulent situation and complex struggle of class interests distracted lots of energy of government to maintain social stability. Similarly, lose control of social stability also had lose a stable foundation of modernization process. Ultimately, the impact of uneven regional development through an inter-related way acted on Thailand's modernization process.

\section{CONCLUSION}

In these two decades, Thailand has experienced a period of rapid economic growth and structural transformation in socioeconomic, industry and urbanization. The driven force of industrial manufacture had led the progress of national economic modernization, and also led Thailand from a traditional agrarian nation into a newly industrializing economy. The diversification of economic structure led Thailand into internationalization, and it provided diverse selection for potential development opportunity. However, the economic boom not only brought the high growth rates of GDP and high speed of urbanization but also triggered a most serious development issue of uneven interregional development.

At first, the structural transformation of socioeconomic driven the development core quickly jumped from agricultural production to industrial manufacturing. At the same time, over concentrated development strategy assembled a pool of foreign investment settled in Bangkok, and the resource allocation was restricted in remote region. The uneven development strategy let a part of people been rich who lived in upper level but widen the income gap and caused a serious income inequality in whole nation. Secondly, the income inequality as a fuse ignited deeper social contradictions subsequently, the gap had widen between rural and urban area not just reflected in income inequality as well including weak living condition, welfare guarantee and educational resources. In consequence, as increasing seriousness gap of social income distribution that a pool of poverty group were left out in the rapid uneven regional development. Ultimately, the influence of uneven development indirectly through a two extremely way to reflected in the Thailand's modernization process.

As a most controversial period of Thailand's modernization, it's difficult to judge this period on one side. The mutual interaction between uneven interregional development and the overall modernization process is not only mutual promotion but also mutual restriction in generally. Strictly speaking, this period which effected by the economic boom has achieved the economic modernization in Bangkok area rather than Thailand. The uneven regional development had led the Thailand's modernization process into an unbalance pattern, and intensified social contradictions. On the other side, this stage of modernization was controversial but also indispensible. Even a series of legacy issue which caused by uneven interregional development has not been solved completely until today, the interaction effect of mutual promotion between regional development and modernization process as well gradually driven the Thailand's into a relatively stable period. There is no doubt that Thailand has paid huge value for increasingly social conflicts which directly or indirectly caused by uneven regional development during last thirty years. And the formation of social obstruction like an interlocking process from quantitative changes to qualitative changes which finally had produced effect of mutual restriction between interregional development and modernization process. But when we review development process of Thailand, after been through all of this transformation, maybe it is a time to find a new path to establish a win-win model to help this nation rebuild confidence for balance national development. 


\section{ACKNOWLEDGMENT}

This research paper was partially supported by International Business School, Yunnan University of Finance and Economics. We thank our colleagues from International Business School and Bangkok Business School who provided insight and expertise that greatly assisted the research, although they may not agree with all of the interpretations of this paper. Also as phased achievement, it is sponsored by Yunnan Provincial Educational Research Project of the $12^{\text {th }}$ Five-Year Plan, Research on Strategical Approach to Constructing Oversea Radiative Centre for Yunnan Cross-border Higher Education (BC15017).

We would also like to show our gratitude to the moderators for sharing their pearls of wisdom with us during the course of this research. And we also immensely grateful to reviewers for their comments on an earlier version of the manuscript. In addition, we would also thank peer reviewer for comments that greatly improved the manuscript.

Last, but not least, We recognize that this research would not have been possible without the financial assistance of the University of Finance and Economics, and other institutions, and express my gratitude to those agencies.

\section{REFERENCES}

[1] Jonathan Rigg, "Southeast Asia: the human landscape of modernization and development," London and New York: Routledge, 1997.

[2] P.P. Pasuk, and B. Chris, "A history of Thailand," New York: Cambridge University Press, 2005.

[3] B. Eliezer, and Ayal, "Thailand and the World: The Transformation to Modernity,” Westport, CT, Praeger Publishers, 1992.

[4] F. Doner, and Richard, "The politics of uneven development: Thailand's economic growth in comparative perspective," Cambridge: Cambridge University Press.
[5] P. Adam, and L.G. Fernando, "Modernization: Theories and Facts," World Politics, vol. 49, 1997, pp. 155-183.

[6] L.D. Bruce, "Metropolis and Nation in Thailand: The Political Economy of Uneven Development," Westview Press, 1980.

[7] S. Chalongphob, "Thailand: uneven economic recovery. Bangkok : Thailand Development Research Institute, 2001.

[8] K. Sauwalak, "Regional development in Thailand: divergence and recent deconcentration,” Bangkok : Thailand Development Research Institute, 1999.

[9] D.X. Chris, "The Thai economy: uneven development and internationalization," London : Routledge, 1999.

[10] P. Pasuk, and B. Chris, "Thailand's boom and bust," Chiang Mai : Silkworm Books, 1998.

[11] I. Shigeru, "The development of manufacturing industry and industrial policy in Thailand," Bangkok: National Research Council of Thailand, 2000.

[12] B.R. Keith, "Reversal of Fortune: East Asia's Economic Crisis is Sending Newly Urbanized Workers Back to their Rural Villages without Jobs or Hope," The Vancouver Sun,1998.

[13] P. O'Hara, "The Encyclopaedia of Political Economy," London, Routledge, 1999.

[14] J.C. Simon, “'The promotion of industry and the planning process', in Thailand: social and economic studies in development," Australian National University, Canberra, 1993, pp. 231-57.

[15] Skill Development Statistic, "Ministry of Labour and Social Welfare," Technical Studies \& Planning, 1997.

[16] Y. Ikemoto, "Income inequality in Thailand in the 1980s," Southeast Asian Studies, vol. 30, 1992, pp. 213-35.

[17] Kitti Limskul, Yukio Ikemoto, "Issues on Income Distribution, Bangkok: Socio-economic Policy and Forecasting Unit," Chulalongkorn University Social Research Institute, 1985.

[18] The Third National Economic and Social Development Plan (19721976). National Economic and Social Development Board.

[19] The Fifth National Economic and Social Development Plan (1982-1986) National Economic and Social Development Board.

[20] The Sixth National Economic and Social Development Plan (19871991), National Economic and Social Development Board.

[21] I. Yukio, and U. Mine, "Income Inequality and Kuznets' Hypothesis in Thailand," Asia Economic journal, vol. 14, 2000. 